\title{
Polymerized Hemoglobin Restores Cardiovascular and Kidney Function in Endotoxin-induced Shock in the Rat
}

\author{
Michael T. Heneka, ${ }^{\star}$ Peter-A. Löschmann, ${ }^{\star \ddagger}$ and Hartmut Osswald ${ }^{\star}$ \\ *Department of Pharmacology, University of Tübingen, Tübingen, Germany; and ${ }^{\ddagger}$ Department of Neurology, Experimental \\ Neuropharmacology, University of Tübingen, Tübingen, Germany
}

\begin{abstract}
Sepsis and its complications, hypotension, shock, and multiorgan failure continue to represent a significant cause of mortality among hospitalized patients, affecting approximately 200,000 patients per year in the US and 100,000 in Europe (Dal Nogare, A.R. 1991. Am. J. Med. Sci. 302:5065.). Incidence rates appear to be increasing, probably due to an increase in the population with risk factors such as diabetes or invasive procedures. Activation of cytokines by endotoxins and subsequent formation of nitric oxide is of central pathogeneic importance in sepsis. In this study we show that polymerized bovine hemoglobin (Biopure 2) restores both cardiovascular and renal functions in an endotoxin-induced shock model in rats. These effects are compared to those of the nitric oxide synthase inhibitor $\mathrm{N}^{\mathrm{G}}$ nitro-L-arginine, and hydroxyethyl starch, the latter currently in clinical use for intravenous volume replacement. Our results clearly indicate that polymerized hemoglobin but not nitric oxide synthase inhibition or volume replacement normalize cardiovascular and kidney function in acute septic shock. This new therapeutic approach is readily applicable to controlled clinical trials because polymerized hemoglobin has been tested in humans and is therefore available for such studies. (J. Clin. Invest. 1997. 99:47-54.) Key words: septic shock $\cdot$ acute renal failure $\cdot \mathrm{N}^{\mathrm{G}}$-nitro-L-arginine $\bullet$ nitric oxide $\bullet$ polymerized hemoglobin
\end{abstract}

\section{Introduction}

Sepsis is a systemic inflammatory response to infection caused by virtually any class of microorganisms. Despite substantial advances in antimicrobial therapy, the mortality of severe sepsis and its complications, hypotension and multiorgan failure, continues to be $\sim 50 \%$, reflecting the limited therapeutic op-

A preliminary report of the data has been presented in poster form at the annual meeting of the American Society of Nephrology, Orlando, FL, 1994.

Address correspondence to Dr. Peter-A. Löschmann, Department of Neurology and Institute of Pharmacology, University of Tübingen, Verfügungsgebäude, Auf der Morgenstelle 15, D-72076 Tübingen. Phone: 497-071-297616 or 7438; FAX: 497-071-296507 or 4942.

Received for publication 29 February 1996 and accepted in revised form 22 October 1996.

J. Clin. Invest.

(C) The American Society for Clinical Investigation, Inc.

0021-9738/97/01/0047/08 \$2.00

Volume 99, Number 1, January 1997, 47-54 tions (1-3). The syndrome is initially characterized by fever, tachycardia, tachypnea, and hypotension. Persisting oliguria, heart failure, and respiratory insufficiency lead to coma and finally death, frequently caused by pulmonary edema with peripheral and central hypoxemia, and disseminated intravascular coagulation. Symptoms arise from a complicated interplay of mediators of cellular function and inflammation, caused by bacteria which possess LPS, peptidoglycan, or lipoteichoic acid as a component of their outer cell membrane. Upon release into the systemic circulation, LPS binds to plasma proteins and lipids activating macrophages to secrete proinflammatory cytokines such as tumor necrosis factor $\alpha$ (TNF $\alpha)$ and IL-1, IL-6, and IL-8 (3). Recently, the ability of cytokines and LPS to stimulate the synthesis of nitric oxide $(\mathrm{NO})^{1}$ by activation of NO-synthase (NOS) in macrophages, neutrophils, endothelial and vascular smooth muscle cells has generated substantial interest (4-7). Three isoforms of NOS have been cloned, sequenced, and expressed, two of which are regulated by intracellular calcium and expressed constitutively in endothelial (cNOS, NOS3) and neuronal cells (bNOS, NOS1), respectively (8). Under physiological conditions cNOS-derived NO, long known as endothelium-derived relaxing factor (EDRF; 9), contributes to maintainance of vascular dilatation and integrity (10). Once produced, NO diffuses to adjacent target cells and activates soluble guanylate cyclase resulting in the formation of $3^{\prime}, 5^{\prime}$-cyclic guanosine monophosphate (cGMP), which mediates many of the biological effects of NO $(11,12)$. Many tissues including vascular smooth muscle cells react to LPS or cytokines by activation of cNOS (NOS1) and de novo synthesis of the inducible isoform (iNOS, NOS2) (13). The latter enzyme is calcium independent and produces large amounts of $\mathrm{NO}$ for prolonged periods of time. NO is now believed to be responsible for the sustained vasodilatation and critical hypotension with reduced vascular responsiveness to vasoconstrictor agents in septic shock (14). The reactivity of NO as a free radical is related to the redox couples it forms with the nitrosonium cation $\left(\mathrm{NO}^{+}\right)$and the nitroxyl anion $\left(\mathrm{NO}^{-}\right)$ both with high reactivity towards molecular oxygen, yielding strongly oxidizing species such as nitrogen dioxide $\left(\mathrm{NO}_{2}\right)$. In

1. Abbreviations used in this paper: GFR, glomerular filtration rate; $\mathrm{Hb}$, hemoglobin; HbNO, nitrosylated hemoglobin; HES, hydroxyethyl starch; hHb, human hemoglobin; HCT, hematocrit; HR, heart rate; MAP, mean arterial blood pressure; NNLA, $\mathrm{N}^{\mathrm{G}}$-nitro-L-arginine; NO, nitric oxide; NOS, nitric oxide synthase; cNOS (NOS3), constitutive endothelial nitric oxide synthase; bNOS (NOS1), constitutive brain nitric oxide synthase; iNOS (NOS2), inducible nitric oxide synthase; $\mathrm{NO}^{+}$, nitrosonium cation; $\mathrm{NO}^{-}$, nitroxyl anion; $\mathrm{NO}_{2}$, nitrogen dioxide; $\mathrm{NO}_{\overline{2}}^{-}$, nitrite; $\mathrm{NO}_{3}$, nitrate; $\mathrm{ONOO}^{-}$, peroxynitrite; $\mathrm{pHb}$, polymerized hemoglobin; SNP, sodium nitroprusside; RBF, renal blood flow; RVR, renal vascular resistance; UF, urinary flow. 
addition, reaction of $\mathrm{NO}$ with $\mathrm{O}_{2}^{-}$results in formation of peroxynitrite $\left(\mathrm{ONOO}^{-}\right)$, rapidly decomposing into the reactive hydroxyl radical and nitrogen dioxide (15). Finally, NO coordinates to transition metals such as manganese, copper, or iron $\left(\mathrm{Fe}^{++}\right.$and $\left.\mathrm{Fe}^{+++}\right)$resulting in inhibition of metalloproteins and enzymes. NO reversibly binds to oxyhemoglobin forming methemoglobin, nitrite $\left(\mathrm{NO}_{2}^{-}\right)$, and nitrate $\left(\mathrm{NO}_{3}\right)$. Deoxyhemoglobin binds $\mathrm{NO}$ with a $10^{6}$-fold higher affinity than $\mathrm{O}_{2}$ resulting in nitrosylated hemoglobin $(\mathrm{HbNO})(16,17)$. In patients with septic shock, high plasma nitrite levels, which indicate NO formation, are positively correlated with plasma endotoxin levels and the reduction of systemic vascular resistance (18-20).

LPS-induced shock in animals, including rats, is widely used to study the pathophysiological effects on cardiovascular, pulmonary, and renal function (21-23). Several factors, including progressive hypotension, compromised oxygen delivery and direct toxic effects of mediators may contribute to organ failure in LPS-induced shock. Experimental endotoxemia is associated with enhanced formation of NO as reflected by subsequent hypotension and increased levels of nitrate and nitrite (24). Many groups reported beneficial effects of NOS inhibitors on cardiovascular function in LPS-induced shock $(21,25)$. However, less is known about the action on organ function and perfusion. Here we compare the effects of the NOS inhibitor $\mathrm{N}^{\mathrm{G}}$-nitro-L-arginine (NNLA) on cardiovascular and renal parameters to those of polymerized hemoglobin ( $\mathrm{pHb}$ ). NNLA stereospecifically inhibits endothelial constitutive NOS and the inducible isoform in vitro (26). Due to its affinity to NO, hemoglobin $(\mathrm{Hb})$ could function as a scavenger to remove exessive amounts of $\mathrm{NO}$ and therefore could be of therapeutic use in septic shock (27). However, Hb itself can induce acute renal failure when infused intravenously $(28,29)$. Polymers of $\mathrm{Hb}$ were originally developed as substitutes for blood transfusion and to improve tissue perfusion and oxygen delivery in hemorrhagic shock (30). The preparation used in our experiments (Biopure 2) is a glutaraldehyde cross-linked bovine hemoglobin $(\mathrm{pHb})$ with an average molecular mass of 200,000 D, is free of endotoxins, phospholipids, or nonhemoglobin proteins and has a vascular persistance of at least $2 \mathrm{~d}$. Because of its molecular weight, $\mathrm{pHb}$ is not filtered and is devoid of renal toxicity. We hypothesized that $\mathrm{pHb}$ acting as a $\mathrm{NO}$-scavenger similar to hemoglobin itself could be of potential interest in experimental septic shock. To control for colloid osmotic effects of $\mathrm{pHb}$, groups of animals were infused with hydroxyethyl starch (HES). Animals treated with physiological saline served as controls.

\section{Methods}

Drugs and solutions. Tritium-labeled inulin $(0.6 \mu \mathrm{Ci} / \mathrm{ml}$, Biotrend, Köln, Germany) and NNLA (Sigma Chemical Corp., St. Louis, MO), sodium nitroprusside (SNP; Merck, Darmstadt, Germany) were dissolved in physiological saline (distilled water containing $0.85 \mathrm{~g} / \mathrm{dl}$ sodium chloride). Suspensions of lipopolysaccharide from Escherichia coli (LPS, serotype 0127:B8; Sigma Chemical Corp.) were prepared in $1.5 \mathrm{ml}$ sterile saline and sonicated for $5 \mathrm{~min}$. Hydroxyethyl starch (HES) $10 \mathrm{~g} / \mathrm{dl}$ (HAES-steril 10\%; Fresenius FAG, Bad Homburg, Germany) was used in the commercially available formulation. Polymerized bovine hemoglobin ( $\mathrm{pHb}$, Biopure 2; Braun Melsungen FAG, Melsungen, Germany) was diluted with saline to a final concentration of $10 \%$. NNLA; HES and pHb or saline were administered in a volume of $1.3 \mathrm{ml} / \mathrm{animal}$. All solutions were pyrogene free and prepared under sterile conditions immediately prior to use. Other reagents were of analytical grade from standard sources.

In vitro experiments. NO concentrations were determined in vitro using a polarimeter (ISO-NO; World Precision Instruments, Inc., Sarasota, FL). Calibration of the probe was done using the titration method provided with the instrument. Briefly, a solution containing $0.1 \mathrm{mM} \mathrm{H}_{2} \mathrm{SO}_{4}, 0.14 \mathrm{M} \mathrm{K}_{2} \mathrm{SO}_{4}$, and $0.1 \mathrm{M} \mathrm{KI}$ was titrated with different concentrations of a $\mathrm{KNO}_{2}$ solution. The signal was registered by a chart recorder and used to construct a six-point calibration curve. SNP was dissolved in $5 \mathrm{ml}$ physiological saline in concentrations of 1.0 or $2.0 \mathrm{mmol}$ and the resulting NO signal was measured continuously. $1 \mathrm{mmol}$ gave a constant production of $1,150 \mathrm{pM}$ NO for $>20 \mathrm{~min}$. This concentration was used to incubate $10 \mu \mathrm{l} \mathrm{pHb} 1 \%$ (final concentration $100 \mathrm{nM}$ ), $10 \mu \mathrm{l}$ HES $1 \%$ (final concentration $100 \mathrm{nM}$ ), $10 \mu \mathrm{l}$ oxygenated human hemoglobin (hHb, Sigma Chemical Corp.; final concentration $100 \mathrm{nM}$ ) or equivalent volumes of saline $7 \mathrm{~min}$ after solution of SNP. NO activity was measured for additional $7 \mathrm{~min}$.

Animal experiments. Male Sprague-Dawley rats (Interfauna, Tuttling, Germany) weighing 250-350 g were housed in groups of four under standard conditions at a temperature of $22^{\circ}\left( \pm 1^{\circ} \mathrm{C}\right)$ and a 12-h light-dark cycle (light on from 600-1800 h). They had free access to standard food pellets (Altromin, Soest, Germany) and tap water. Experiments were conducted between 900 and $1700 \mathrm{~h}$. Thiopentone anesthesia was induced by intraperitoneal administration of $80 \mathrm{mg} /$ $\mathrm{kg}$. Animals were placed on a water-heated, temperature-controlled surgical board. Body temperature was monitored with an electronic rectal probe (Lauda, Königshofen, Germany) and kept constant at $37^{\circ} \mathrm{C}$ throughout the experiment. After tracheotomy the right jugular vein was cannulated with a polyethylene catheter for saline infusion $(1 \mathrm{ml} / \mathrm{h})$ and drug administration. A second catheter was placed into the same vein for infusion of inulin $(2 \mathrm{ml} / \mathrm{h})$ to measure the glomerular filtration rate (GFR). The right femoral artery was cannulated for continuous monitoring of mean arterial blood pressure (MAP) and heart rate (HR) using a pressure transducer (Gould Inc., Cleveland, $\mathrm{OH})$ and to collect blood samples. After a flank incision the left kidney was cautiously freed from adhering fat and embedded in a plastic holder and covered with saline wetted cotton, the left ureter was cannulated for collection of urine samples and the left renal artery was exposed to place an electromagnetic flow probe (Carolina Medical Electronics, King, NC) to monitor renal blood flow. At the end of the experiments animals were killed by an overdose of thiopental and the kidneys were removed for histological examination.

Animal experiments comprised of the surgery followed by an equilibration period $(70 \mathrm{~min})$ and three subsequent 1 -h intervals to monitor baseline conditions, the endotoxin induced shock and the effects of treatments. GFR, renal blood flow (RBF), urinary flow (UF), and excretion of sodium and potassium were determined in 20-min intervals from min 40-60 during the baseline, shock, and treatment periods. Blood samples $(80 \mu \mathrm{l})$ were collected for determination of hematocrit (HCT) and inulin at 30 and $50 \mathrm{~min}$ in each period. To induce septic shock, LPS was administered at a dose of $20 \mathrm{mg} / \mathrm{kg}$ in $1.0 \mathrm{ml}$ by intravenous injection over $3 \mathrm{~min}$ at the end of the baseline period. $60 \mathrm{~min}$ later, groups of animals were randomly allocated for treatment with $\mathrm{pHb}(10 \%, 1.3 \mathrm{ml} / 300 \mathrm{~g}$ body wt, i.e., $\sim 4 \mathrm{mg} / \mathrm{kg}$, group 1$)$, HES $(10 \%, 1.3 \mathrm{ml} / 300 \mathrm{~g}$ body wt, group 2$)$, saline $(1.3 \mathrm{ml} / 300 \mathrm{~g}$ body wt, group 3 ) or NNLA (30 $\mu \mathrm{mol} / \mathrm{kg}$, group 4$)$. All compounds were infused i.v. over $6.5 \mathrm{~min}$. All experiments were carried out in accordance with the recommendations of the Declaration of Helsinki and the animal welfare guidelines and laws of the Federal Republic of Germany and were approved by the local ethical committee for animal experiments.

Statistical analyses. Differences between baseline and shock periods for all parameters were statistically analyzed using Student's $t$ test for paired samples. Alpha adjustments for multiple tests were performed according to a standard procedure (31). Similarly, baseline values were compared to treatment effects using Student's $t$ test for animals subjected to the experimental procedure without administration of LPS. Baseline, shock, and treatment effects were subjected to 

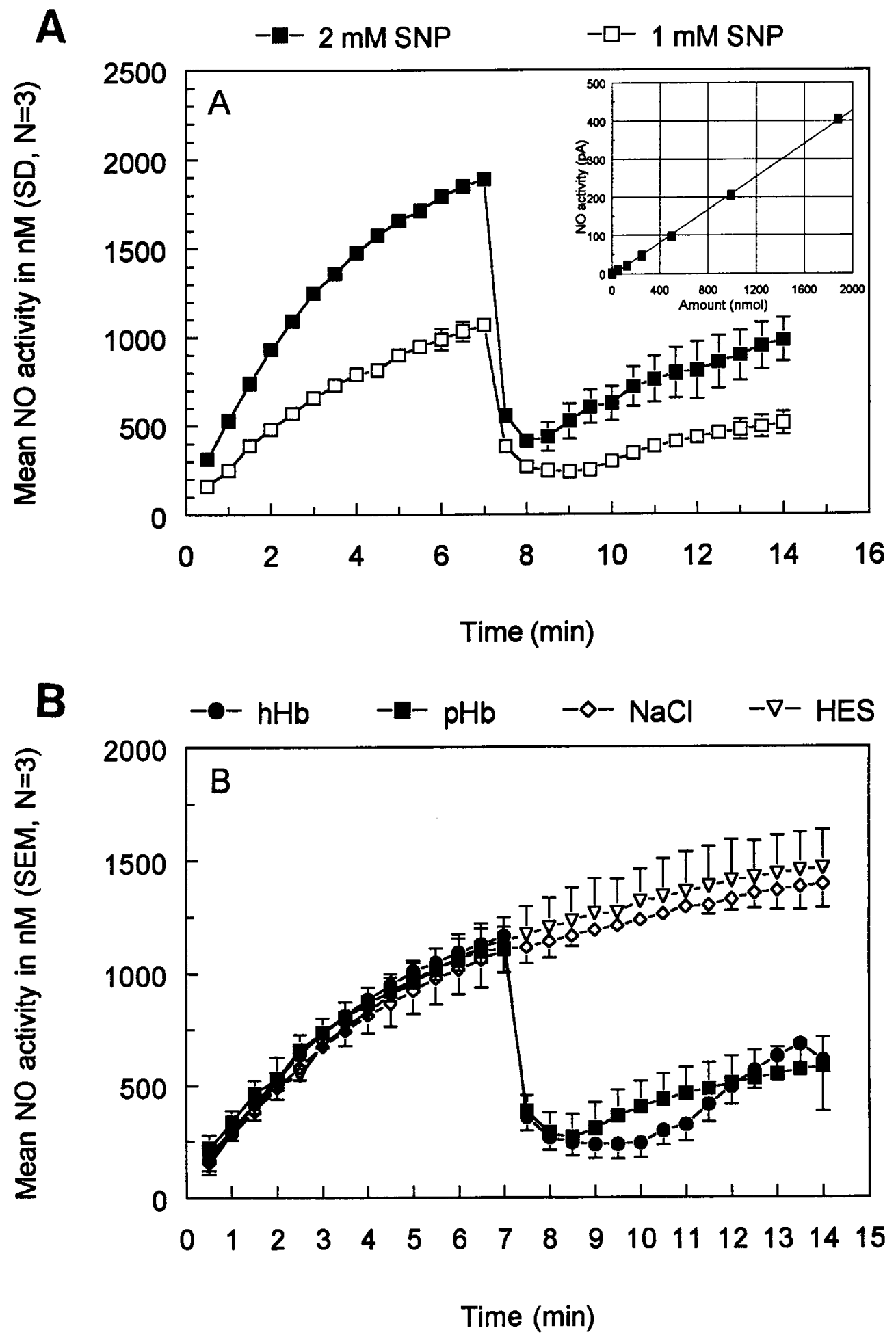

Figure 1. (A) Mean NO activity released by 1 (open squares) or 2 (closed squares) $\mathrm{mM} \mathrm{SNP} \mathrm{in}$ vitro before ( $\min 0-7)$ and after (min 7-14) incubation with $100 \mathrm{nM} \mathrm{pHb}$. Depicted are the mean values and SD of three independent experiments. (Inset) Calibration curve for triplicate determinations of six known NO concentrations $\left(r^{2}=0.99\right)$. This curve was used for determination of NO activity in subsequent experiments. (B) Mean NO activity released by $1 \mathrm{mM}$ SNP in vitro before (min 0-7) and after (min 7-14) incubation with $100 \mathrm{nM}$ human hemoglobin (closed circles), $100 \mathrm{nM}$ polymerized bovine hemoglobin (closed squares), saline (open diamonds), or hydroxyethyl starch (open triangles). Depicted are the mean values and SEM of three independent experiments.

one way repeated measurement ANOVA with one grouping factor with three repeated measures. Post hoc analyses were calculated to explore differences between groups and times of measurement when appropriate. All $P$ values given for the effects containing repeated measurements are adjusted according to Huynh and Feldt (SYSTAT, Evanston, IL). Values are expressed as means \pm SEM of $n$ observations, where $n$ represents the number of the animals. Mean values and SEM of measurements were calculated for each time point.

\section{Results}

Polarimetric measurement of NO activity was used to construct a six-point calibration curve with triplicate measures for each NO concentration (insert, Fig. 1). The detection limit (signal to noise ratio $\geq 3$ ) of the method was $30 \mathrm{pM}$ and a linear signal obtained up to $1.88 \mu \mathrm{M}\left(r^{2}=0.99\right)$. Solution of sodium 


\begin{tabular}{|c|c|c|c|c|c|c|}
\hline & \multicolumn{2}{|c|}{$\begin{array}{l}\text { Hydroxyethyl starch } \\
\text { (HES) }\end{array}$} & \multicolumn{2}{|c|}{$\begin{array}{c}\mathrm{N}^{\mathrm{G}} \text {-nitro-L-arginine } \\
\text { (NNLA) }\end{array}$} & \multicolumn{2}{|c|}{$\begin{array}{l}\text { Polymerized hemoglobin } \\
(\mathrm{pHb})\end{array}$} \\
\hline & Baseline & Treatment & Baseline & Treatment & Baseline & Treatment \\
\hline $\begin{array}{l}\text { MAP } \\
\qquad(\mathrm{mmHg})\end{array}$ & $95.2(4.1)$ & $92.0(6.8)$ & $92.7(2.3)$ & $129.3(2.5)^{\ddagger}$ & $90.0(3.3)$ & $104.5(3.2)^{*}$ \\
\hline $\begin{array}{l}\text { HR } \\
\text { (bpm) }\end{array}$ & $358(12.0)$ & $378(24.8)$ & $367(10.0)$ & $348(19.0)$ & $358(16.6)$ & $357(15.0)$ \\
\hline HCT & $46.6(0.7)$ & $44.4(0.6)^{*}$ & $45.8(0.7)$ & $49.6(0.6)^{*}$ & 47 (1.0) & $46.4(0.9)$ \\
\hline $\begin{array}{l}\text { GFR } \\
\qquad(\mu \mathrm{l} / \mathrm{min})\end{array}$ & $814(99)$ & $1080(106)^{*}$ & $919(79)$ & $892(71)$ & 867 (97) & $1246(263)$ \\
\hline $\begin{array}{l}\mathrm{RBF} \\
\qquad(\mathrm{ml} / \mathrm{min})\end{array}$ & $5.4(0.6)$ & $7.5(0.7)$ & $6.4(1.0)$ & $3.2(0.4)^{*}$ & $5.4(0.5)$ & $5.4(0.6)$ \\
\hline $\begin{array}{l}\text { RPF } \\
\qquad(\mathrm{ml} / \mathrm{min})\end{array}$ & $2.9(0.3)$ & $4.2(0.4)^{\ddagger}$ & $3.5(0.6)$ & $1.6(0.2)^{*}$ & $2.9(0.3)$ & $2.9(0.3)$ \\
\hline $\begin{array}{l}\text { RVR } \\
\qquad(\mathrm{mmHg} / \mathrm{ml} / \mathrm{min})\end{array}$ & $18.7(2.7)$ & $12.7(1.5)$ & $15.9(2.6)$ & $42.9(5.7)^{\ddagger}$ & $17.3(2.1)$ & $20.0(2.6)^{*}$ \\
\hline $\begin{array}{l}\text { UF } \\
\qquad(\mu \mathrm{l} / \mathrm{min})\end{array}$ & $5.3(0.9)$ & $35.3(12.4)$ & $5.9(2.3)$ & $42.7(13.3)^{*}$ & $3.5(0.1)$ & $17.4(3.7)^{*}$ \\
\hline
\end{tabular}

Animals were subjected to all experimental procedures, except for LPS infusion. Given are mean values with standard errors in parentheses for the parameters measured in min $20-40$ of the baseline and treatment period $(n=5$ per group). Superscripts indicate significant differences between the shock period vs. baseline condition $\left({ }^{*} P<0.05,{ }^{\ddagger} P<0.01 ; t\right.$ test for paired samples).

nitroprusside (SNP) in saline resulted in NO activity increasing gradually over time. The signal was concentration-dependent and reached a plateau after $7 \mathrm{~min}$. NO released by 1 or $2 \mathrm{mM}$ SNP was inhibited by $\mathrm{pHb} 100 \mathrm{nM}$ in vitro. The effect was maximal at $1 \mathrm{~min}$ and a more than $50 \%$ reduction was still present at $7 \mathrm{~min}$ (Fig. $1 \mathrm{~A}$ ). Under identical conditions HES $(100 \mathrm{nM})$ and saline had no effect, but NO activity increased slightly further, whereas $\mathrm{hHb}(100 \mathrm{nM})$ had an effect similar to pHb (Fig. $1 B$ ).

Cardiovascular and renal effects of $\mathrm{pHb}, \mathrm{HES}$, sodium chloride, or NNLA were studied first in groups of 5 animals under experimental conditions, but without injection of LPS (Table I). Parameters recorded from min 40-60 of the baseline period are compared to those of min 40-60 after treatment. Treatment of control rats with HES increased both GFR and RPF and resulted in a decreased HCT. HR, renal vascular resistance (RVR), and UF were increased in animals treated with $\mathrm{pHb}$ or NNLA. In addition, treatment with NNLA decreased RBF and RPF, but increased HCT.

Administration of LPS led to symptoms of shock within 60 min. The syndrome is characterized by an increased HR, reduction of mean MAP and RBF, increased RVR, and a reduced GFR resulting in anuria. Because no differences were evident between groups, the effects of LPS on the parameters measured in min 40-60 of the baseline and shock period are summarized for all groups in Table II. Similar results were obtained for min 20-40 of both periods (data not shown). Given are the mean values for MAP and HR of all animals of this study $(n=50)$ and the subgroup of animals $(n=27)$ in which in addition to RVR, GFR, RBF, HCT, and UF were measured (Figs. 2 and 3). The LPS-induced shock is lethal to approximately $25 \%$ of animals treated with saline within $2 \mathrm{~h}$ under these conditions.

The effects of LPS and subsequent infusion of $\mathrm{pHb}, \mathrm{HES}$, saline, or NNLA in groups of 12 or 13 animals upon MAP and
HR as well as RVR, HCT, GFR, RBF, RPF, and UF for six to seven animals per group are illustrated in Figs. 2 and 3. To control for group effects, baseline values and those of the shock period were compared for all measures. Although there is some variability of the mean values, none of the differences reached the level of statistical significance. Within the treatment period 3 out of 12 animals died in the saline group and 1 animal died following treatment with NNLA. Administration of $\mathrm{pHb}$ and less pronounced of NNLA resulted in rise of MAP accompanied by normalization of heart rate, both values being significantly different from the saline control. Treatment with

Table II. Effects of LPS-Induced Shock on Cardiovascular and Renal Function

\begin{tabular}{lccc}
\hline & & $\begin{array}{c}\text { Baseline } \\
\text { (mean, SEM) }\end{array}$ & $\begin{array}{c}\text { Shock } \\
\text { (mean, SEM) }\end{array}$ \\
\hline Mean arterial pressure (MAP, mmHg) & 50 & $103.6(1.8)$ & $66.9(2.1)^{*}$ \\
Heart rate (HR, beats/min) & 50 & $375.9(4.1)$ & $423.2(5.0)^{*}$ \\
Hematocrit (HCT) & 27 & $46.1(0.4)$ & $50.6(0.9)^{*}$ \\
Glomerular filtration rate & 27 & $734.7(41.0)$ & $87.3(32.4)^{*}$ \\
$\quad(\mathrm{GFR}, \mu \mathrm{l} / \mathrm{min})$ & & & \\
Renal blood flow (RBF, ml/min) & 27 & $5.7(0.3)$ & $2.5(0.3)^{*}$ \\
Renal plasma flow (RPF, ml/min) & 27 & $3.0(0.2)$ & $1.3(0.1)^{*}$ \\
Renal vascular resistance & & & \\
$\quad(\mathrm{RVR}, \mathrm{mmHg} / \mathrm{ml} \mathrm{per} \mathrm{min)}$ & 27 & $18.6(1.1)$ & $53.9(15.0)$ \\
Urinary flow (UF, $\mu \mathrm{l} / \mathrm{min})$ & 27 & $10.2(1.5)$ & $0.8(0.2)^{*}$
\end{tabular}

Given are mean values with standard errors in parentheses for the parameters measured in min 20-40 of the baseline and shock period. Asterisks indicate significant differences between the shock period vs. baseline condition $\left[{ }^{*} P<0.01, t\right.$ test for paried samples, alpha adjustment for repeated tests was performed according to a standard method (30)]. 

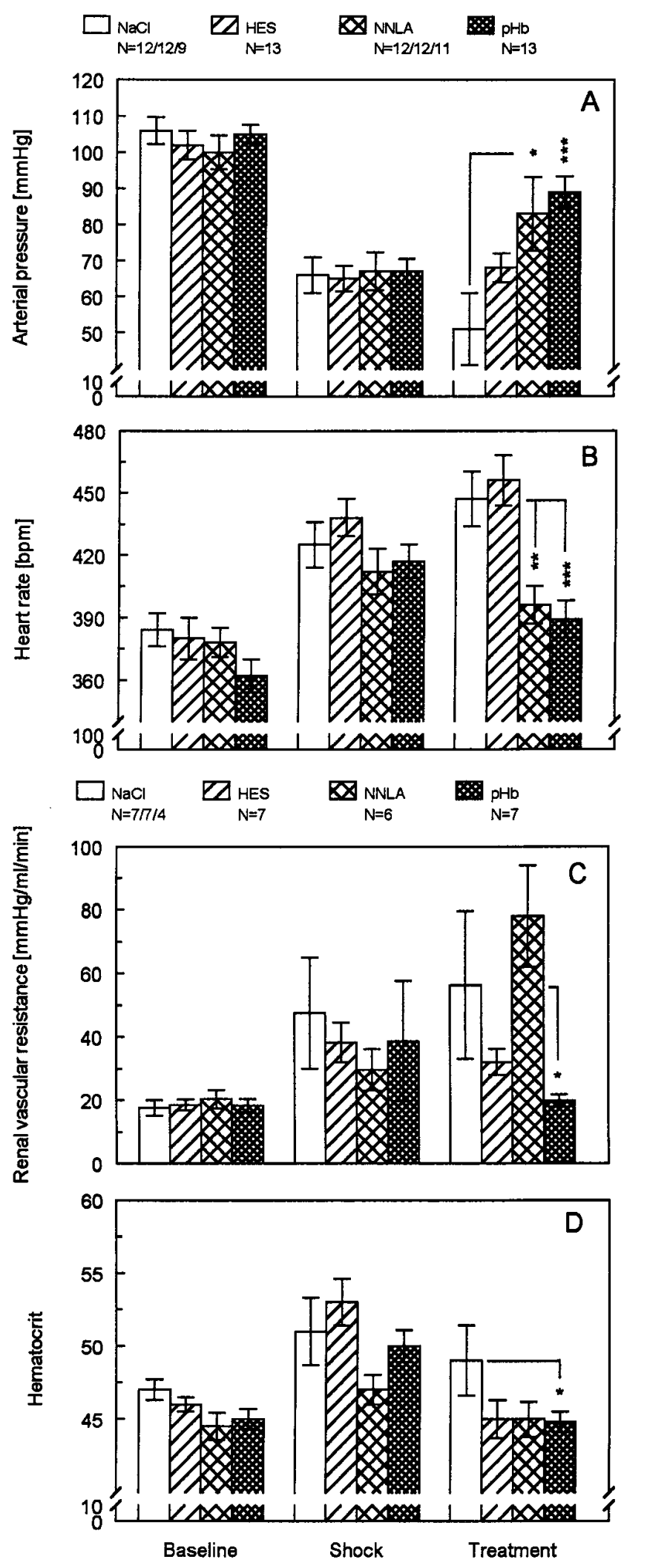

Figure 2. Effects of treatment with saline, HES, NNLA, or $\mathrm{pHb}$ on cardiovascular and renal function. Mean values with SEM for $(A)$ MAP, $(B) \mathrm{HR},(C) \mathrm{RVR}$, and $(D)$ HCT measured in min 20-40 of the baseline, shock, and treatment period. Asterisks indicate significant differences between groups within the baseline, shock, or treatment period vs. saline treated animals ( $* P<0.05, * * P<0.01$, $\left.{ }^{* * *} P<0.001\right)$.
HES had no effect on MAP or heart rate. Renal vascular resistance was reduced in tendency by HES, whereas treatment with NNLA further increased RVR. The increase of RVR caused by NNLA did not reach the level of statistical significance due to the variability of data in the saline group caused by agony: three out of seven animals treated with saline died within the first $20 \mathrm{~min}$ of the treatment period. Treatment with pHb completely normalized RVR to baseline values. HCT was decreased by all treatments when compared to the saline group, although only the measures for the group treated with $\mathrm{pHb}$ reached the level of statistical significance. GFR, RBF, and RPF were normalized to preshock levels only by $\mathrm{pHb}$ treatment (Fig. 3). Urinary flow was increased by treatment with both $\mathrm{pHb}$ and NNLA. However, the effect of the latter was inconsistent, resulting in variability of the data.

\section{Discussion}

Septic shock is a complex syndrome affecting many metabolic pathways and endocrinological functions. NO has a number of physiological functions including a key role in host defense mechanisms. It is the overproduction of NO in septic shock and its role as final pathway of cytokine-mediated effects that makes this molecule a major target for therapeutic intervention in endotoxemia. The critical involvement of iNOS (NOS2) in LPS-induced shock is emphasized by a recent study showing that iNOS-deficient transgenic mice are resistant to LPSinduced mortality (32). We used intravenous infusion of LPS to induce septic shock in rats. Because rodents are relatively resistant to LPS, high doses were required to induce sustained hypotension and acute renal failure, making it difficult to translate the model directly to the clinical situation. However, this model reflects at least important aspects of the pathophysiological changes seen in human septic shock.

The use of hemoglobin solutions prepared by lysis of red blood cells as substitute for blood transfusion was associated with serious side effects including kidney failure, intravascular coagulation, and anaphylactic reactions $(28,29)$. Purification to remove erythrocyte stroma or contaminating lipopolysaccharide reduces but does not prevent toxicity because hemoglobin causes renal failure by intratubular precipitation of methemoglobin and free heme (33). Chemical modifications forming intratetrameric cross-links were introduced to prevent hemoglobin tetramers from dissociation thereby minimizing the filtration of hemoglobin at the glomerulus, and to shift the oxygen dissociation curve to the right, i.e., to obtain $\mathrm{O}_{2}$ dissociation constants similar to whole blood. Such preparations were effective in models of hemorrhagic shock $(34,35)$. Genuine and cross-linked human hemoglobins bind to bacterial endotoxins resulting in significant toxicity $(36,37)$. Therefore, hemoglobin itself and polymerized hemoglobins $(\mathrm{pHb})$, with molecular weights in the range of 200,000 D, have not been tested in LPS-induced shock. We used a preparation that does not activate the complement system and has no effect on platelet aggregation or renal function (30).

Reports by others (38) using inoculation with living $E$. coli to induce sepsis and a different hemoglobin preparation demonstrate deleterious effects of this treatment. However, these results were not confirmed using another hemoglobin preparation (39). These discrepancies indicate pharmacodynamic differences of the hemoglobin preparations used (39). Our data show that $\mathrm{pHb}$ (Biopure 2) does not aggravate LPS toxicity in vivo but could serve as therapeutic agent in septic shock. 

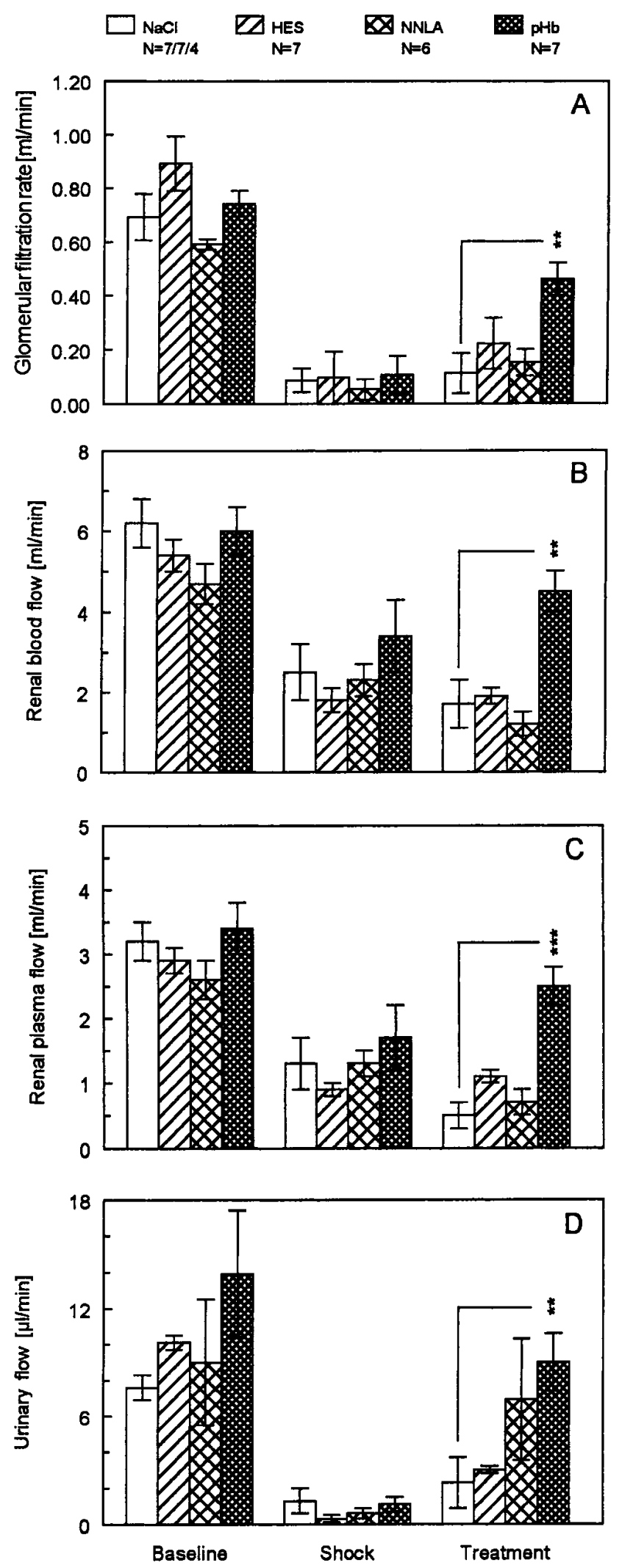

Figure 3. Effects of treatment with saline, HES, NNLA, or $\mathrm{pHb}$ on renal function. Mean values with SEM for $(A) \mathrm{GFR},(B) \mathrm{RBF},(C)$ $\mathrm{RPF}$, and $(D)$ UF measured in min 20-40 of the baseline, shock, and treatment period. Asterisks indicate significant differences between groups within the baseline, shock, or treatment period vs. salinetreated animals $(* P<0.05, * * P<0.01)$.
Direct measurement of NO in vitro shows that nanomolar concentrations of $\mathrm{hHb}$ and $\mathrm{pHb}$ remove $\mathrm{NO}$, generated by millimolar concentrations of SNP. Although the molecular basis of the complex chemical reactions involved remains to be resolved, we concluded that polymerization of hemoglobin did not substantially reduce its affinity to $\mathrm{NO}$ as compared to hemoglobin.

Under the experimental conditions employed here, the cardiovascular and renal responses to hypotensive shock were apparent before treatment was initiated. Cardiovascular and renal parameters were measured simultaneously from one rat. This design was chosen to exclude interference of the test compounds with the bioavailability or effects of LPS, and to model the clinical situation.

Treatment of control animals with HES decreased HCT and increased GFR and RPF reflecting the colloid osmotic expansion of blood volume (Table I). Blood pressure and heart rate were at pretreatment levels. Similar to its methyl ester (40), NNLA increased blood pressure and RVR, accompanied by a reduction of RBF and RPF. This is explained by vasoconstriction and platelet aggregation due to the absence of $\mathrm{NO}$ (40). Under these conditions $\mathrm{pHb}$ tended to cause similar effects on MAP, RVR, and UF. In contrast to NNLA, RBF, $\mathrm{RPF}$, and HCT remained at basal values. This could indicate that regulation of vascular tone was principally intact, but due to $\mathrm{pHb}$ 's high affinity to $\mathrm{NO}$, removal of endogenous basal NO induced some vasoconstriction.

The impairment of cardiovascular and renal function after LPS infusion shows that the shock induced was rapid and severe (Table II), and is also reflected by the mortality in the saline group. The increase in MAP after treatment with $\mathrm{pHb}$ was significantly higher in LPS-treated rats than in control animals (Table I; Fig. 2) indicating that $\mathrm{pHb}$ attenuates the effect of a vasodilator autacoid overproduction in early endotoxemia. As an enhanced formation of nitric oxide by cNOS (NOS3, early phase of septic shock) and iNOS (NOS2, late phase of septic shock) accounts for acute and sustained vasodilatation in endotoxemia (5) we propose that the beneficial effects of $\mathrm{pHb}$ are due to scavenging endogenous NO. Although we did not measure iNOS (NOS2) mRNA or peptide, it is very likely that under the conditions employed here, i.e., intravenous administration of $20 \mathrm{mg} / \mathrm{kg}$ LPS, iNOS (NOS2) was induced. However, the enzymatic activity probably had not reached maximal levels at 120 min after injection of LPS.

Neither MAP nor HR were beneficially influenced by treatment with HES. Thus, colloid osmotic effects and volume replacement have no effect in this model. Because the colloid osmotic pressure of HES (27 $\mathrm{mmHg}$ ) was even higher than of $\mathrm{pHb}(21 \mathrm{mmHg})$, colloid osmotic properties cannot account for the effects of $\mathrm{pHb}$. LPS-induced hypotension and reflex tachycardia were corrected by the NOS inhibitor NNLA and, more effectively, by treatment with $\mathrm{pHb}$. These findings are in accord with those of others showing beneficial effects of NOS inhibitors such as $\mathrm{N}^{\mathrm{G}}$-monomethyl-L-arginine (L-NMMA) or $\mathrm{N}^{\mathrm{G}}$-nitroarginine methyl ester (L-NAME) in septic shock with respect to HR and MAP.

In our model hypotension reduced renal perfusion pressure below the autoregulatory range $(<70 \mathrm{mmHg})$ resulting in an oliguric-anuric acute renal failure. Under these conditions GFR falls proportionally to decreases in MAP. Although both $\mathrm{pHb}$ and NNLA normalized MAP only $\mathrm{pHb}$ increased GFR, $\mathrm{RBF}$, and RPF close to baseline values. NNLA reduced the al- 
ready compromised $\mathrm{RBF}$ and $\mathrm{RPF}$ even further to $50 \%$ of shock period values. This resulted in an 2.5 -fold increase in renal vascular resistance, leaving GFR on shock values unchanged. The increase in mean UF after NNLA treatment (Fig. $2 D$ ) is produced by a single animal which had a surprisingly high urine excretion and is therefore artificial. All other animals had very low urinary flow rates.

Dose-dependent, beneficial as well as deleterious effects of NOS inhibitors in LPS-induced shock have been reported. Results of a dose-response study using L-NMMA in rats showed that doses of $300 \mathrm{mg} / \mathrm{kg}$ are detrimental, whereas $3 \mathrm{mg} / \mathrm{kg}$ are ineffective to affect blood pressure in septic shock. Therefore, the dose of NNLA employed in our single-dose study is of major importance. NNLA is the active metabolite of L-NAME, a compound widely used for studies similar to ours (41). The dose of NNLA employed here $(30 \mu \mathrm{mol} / \mathrm{kg}$, i.e., $6.5 \mathrm{mg} / \mathrm{kg}$ i.v. $)$ is within the dose range shown to be effective by others.

Due to their effects on blood pressure and vascular function the potential usefulness of NOS inhibitors such as arginine derivatives or Methylene blue for treatment of septic shock has been advocated by several groups. However, our data and the results of Lorente et al., (42) suggest that unselective NOS inhibitors may be deleterious for renal function in septic shock. A limited number of clinical studies using L-NMMA, L-NAME, NNLA, or Methylene blue (43) support this conclusion: despite the increase in MAP, accompanied by increased vascular resistance and a partial restoration of vascular reactivity to noradrenaline, favorable effects on survival were not reported. These disappointing results may be explained in part by selection criteria as only patients in critical condition were treated. However, the results of our study indicate that NO inhibitors have no beneficial effects but further impair renal function in endotoxin shock.

The most important observation of the present study is that treatment with NNLA and $\mathrm{pHb}$ differentially interfere with renal function in septic shock. Both compounds restore MAP and HR to baseline values but NNLA further impairs RBF flow and thus RVR. Renal function including GFR and UF are normalized close to baseline values by $\mathrm{pHb}$. This could be explained by their different effects on NO function. NNLA blocks NO formation by inhibiting uniformly both cNOS (NOS3) and iNOS (NOS2) in all tissues whereas pHb scavenges NO without leaving the vessels. Inactivation of intravascular NO will result in a concentration gradient directed to the blood vessels and thereby reduce interstitial NO concentrations, leaving NO production principally intact. It has been described recently that neuronal type NOS (NOS1) is expressed in macula densa cells $(44,45)$. These specialized tubular cells are in close contact with the vascular pole of the glomerulus and are proposed to contribute to the regulation of vascular resistance of afferent arterioles by releasing NO. Because $\mathrm{pHb}$ is not filtered under normal conditions and in septic shock NO activity generated by these cells will remain unaffected, it follows that inhibition of NOS by NNLA might compromise this important regulatory function. In addition NNLA would also remove NO necessary to prevent endotoxin-induced renal thrombosis (46).

Impairment of renal function is critically involved in the pathophysiological sequale in septic shock finally resulting in multiorgan failure. Restoration of kidney perfusion and cardiovascular function should improve therapeutic benefit. Because $\mathrm{pHb}$ has already been tested in humans it would be available for clinical studies. Our results clearly indicate that treatment with $\mathrm{pHb}$ but not with unselective NOS inhibitors could improve both renal and cardiovascular function in patients suffering from septic shock.

\section{Acknowledgments}

The authors thank R. Grundmann (Braun-Melsungen, FRG) for providing $\mathrm{pHb}$ (Biopure 2), K. Stieler for technical assistance, and Dr. M.M. Schugens for statistical advice. We also thank J. Werringloer for advice and productive discussions.

\section{References}

1. Dal Nogare, A.R. 1991. Southwestern Internal Medicine Conference: septic shock. Am. J. Med. Sci. 302:50-65.

2. Bone, R.C. 1994. Sepsis and its complications: The clinical problem. Crit. Care Med. 22:S8-S11.

3. Parillo, J.E. 1993. Pathogenetic mechanisms of septic shock. N. Engl. J. Med. 328:1471-1477.

4. Redl, H., G. Schlag, R. Kneidinger, W. Öhlinger, and J. Davies. 1994. Response of the endothelium to trauma and sepsis. Drug Res. 44:443-446.

5. Thiemermann, C. 1994. The role of the L-arginine: nitric oxide pathway in circulatory shock. Adv. Pharmacol. 28:45-79.

6. Beasley, D., and M. Eldridge. 1994. Interleukin-1 beta and tumor necrosis factor-alpha synergistically induce NO synthase in rat vascular smooth muscle cells. Am. J. Physiol. 266:R1197-R1203.

7. Cunha, F.Q., J. Assreuy, D.W. Moss, D. Rees, L.M. Leal, S. Moncada, M. Carrier, C.A. O'Donnell, and F.Y. Liew. 1994. Differential induction of nitric oxide synthase in various organs of the mouse during endotoxaemia: role of TNF-alpha and IL-1-beta. Immunology. 81:211-215.

8. Förstermann, U., E.I. Closs, J.S. Pollock, M. Nakane, P. Schwarz, I. Gath, and H. Kleinert. 1994. Nitric oxide synthase isozymes. Characterization, purification, molecular cloning, and functions. Hypertension. 23:1121-1131.

9. Furchgott, R.F., and J.V. Zawadziki. 1980. The obligatory role of endothelial cells in the relaxation of arterial smooth muscle cells by acetylcholine. Nature (Lond.). 288:373-376.

10. Moncada, S., and A. Higgs. 1993. The L-arginine-nitric oxide pathway. N. Engl. J. Med. 329:2002-2012.

11. Knowles, R.G., M. Palacios, R.M. Palmer, and S. Moncada. 1989. Formation of nitric oxide from L-arginine in the central nervous system: a transduction mechanism for stimulation of the soluble guanylate cyclase. Proc. Natl. Acad. Sci. USA. 86:5159-5162.

12. Rosenberg, R.B., C.W. Broner, and M.S. O’Dorisio. 1994. Modulation of cyclic guanosine monophosphate production during Escherichia coli septic shock. Biochem. Med. Metab. Biol. 51:149-155.

13. Szabo, C., J.A. Mitchell, C. Thiemermann, and J.R. Vane. 1993. Nitric oxide-mediated hyporeactivity to noradrenaline precedes the induction of nitric oxide synthase in endotoxin shock. Br. J. Pharmacol. 108:786-792.

14. Julou-Schaeffer, G., G. Gray, I. Fleming, C. Schott, J.R. Parratt, and J.C. Stoclet. 1991. Activation of the L-Arginine-Nitric Oxide Pathway is Involved in Vascular Hyporeactivity Induced by Endotoxin. J. Cardiovasc. Pharmacol. 17(Suppl. 3):S207-S212.

15. Beckman, J.S., T.W. Beckman, J. Chen, P.M. Marshall, and B.A. Freeman. 1990. Apparent hydroxyl radical production by peroxynitrite: implications for endothelial injury from nitric oxide and superoxide. Proc. Natl. Acad. Sci. USA. 87:1621-1624.

16. Henry, Y., M. Lepoivre, J.-C. Drapier, C. Ducroq, J.-L. Boucher, and A. Guissani. 1993. EPR characterization of molecular targets for NO in mammalian cells and organelles. FASEB J. 7:1124-1134.

17. Knowles, R.G., and S. Moncada. 1992. Nitric oxide as signal in blood vessels. TIBS. 17:399-402.

18. Ochoa, J.B., B. Curti, and A.B. Peitzmann. 1992. Increased circulating nitrogen oxides after human tumor immunotherapy: Correlation with toxic hemodynamic changes. J. Natl. Cancer Inst. 84:864-867.

19. Evans, T.E., A. Carpenter, H. Kindermann, and J. Cohen. 1993. Evidence of increased nitric oxide production in patients with sepsis syndrome. Circ. Shock. 41:77-81.

20. Ochoa, J.B., A.O. Udekwu, and T.R. Biliar. 1991. Nitrogen oxide levels in patients after trauma and during sepsis. Ann. Surg. 214:621-626.

21. Thiemermann, C., and J. Vane. 1990. Inhibiton of nitric oxide synthesis reduces the hypotension induced by bacterial lipopolysaccharides in the rat in vivo. Eur. J. Pharmacol. 182:591-595.

22. Lorente, J.A., M.A. Renes, M.A. Gómez-Aguinaga, L. Landín, and D. Liste. 1991. Oxygen delivery-dependent oxygen consumption in acute respiratory failure. Crit. Care Med. 19:773-777.

23. Zager, R.A. 1986. Escherischia coli endotoxin injections potentiate ischemic renal injury. Am. J. Physiol. 251:F988. 
24. Brady, A.J., and P.A. Poole Wilson. 1993. Circulatory failure in septic shock. Nitric oxide: too much of a good thing? Br. Heart J. 70:103-105.

25. Stoclet, J.C., I. Fleming, G. Gray, G. Julou-Schaeffer, F. Schneider, C. Schott, and J.R. Parratt. 1993. Nitric Oxide in Endotoxemia. Circulation. 87:77-80.

26. Mülsch, A., and R. Busse. 1990. $\mathrm{N}^{\mathrm{G}}$-nitro-L-arginine $\left(\mathrm{N}^{5}\right.$-[imino(nitromino)methyl]-L-ornithine) impairs endothelium-dilatations by inhibiting cytosolic nitric oxide synthesis from L-arginine. Naunyn-Schmiederbergs Arch. Pharmakol. 341:143-147.

27. Martin, W., D. Villani, D. Jothianandan, and R.F. Furchgott. 1985. Selective blockade of endothelium-dependent and glyceryl trinitrate-induced relaxation by hemoglobin and by methyleneblue in the rabbit aorta. J. Pharmacol. Exp. Ther. 232:708-716.

28. Amberson, W.R., J.J. Jennings, and C.M. Rhode. 1949. Clinical experience with hemoglobin-saline solutions. J. Appl. Physiol. 1:469-489.

29. Braun, S., F. R. Weiss, A. Keller, J.R. Ciccone, and H.G. Preuss. 1969. Evaluation of the renal toxicity of heme proteins and their derivatives: a role in the genesis of acute tubular necrosis. J. Exp. Med. 129:909-924.

30. Rausch, C.W., and M. Feola. 1992. No. 0277289. European Patent.

31. Holm, S. 1979. A simple sequentially rejective multiple test procedure. Scand. J. Statist. 6:65-70.

32. Wei, X.-Q., I.G. Charles, A. Smith, J. Ure, G.J. Feng, F.P. Huang, D. Xu, W. Muller, S. Moncada, and F.Y. Liew. 1995. Altered immune responses in mice lacking inducible nitric oxide synthase. Nature (Lond.). 375:408-411.

33. Zager, R.A., and L.M. Gamelin. 1989. Pathogenetic mechanisms in experimental hemoglobinuric acute renal failure. Am. J. Physiol. 256 (3 Pt 2): F446-F455.

34. Thompson, A., A.E. McGarry, C.R. Valeri, and W. Lieberthal. 1994. Stroma-free hemoglobin increases blood pressure and GFR in the hypotensive rat: role of nitric oxide. J. Appl. Physiol. 77:2348-2354.

35. Dunlap, E., L. Farrell, C. Nigro, T. Estep, G. Marchland, and K. Burhop. 1995. Resuscitation with diaspirin crosslinked hemoglobin in a pig model of hemorrhagic shock. Artif. Cells, Blood Substit. and Immobil. Biotechnol. 23:39-61.
36. Kaca, W., R.I. Roth, and J. Levin. 1994. Hemoglobin, a newly recognized lipopolysaccharide (LPS)-binding protein that enhances LPS biological activity. J. Biol. Chem. 269:25078-25084.

37. White, C.T., A.J. Murray, D.J. Smith, J.R. Greene, and R.B. Bolin. 1986. Synergistic toxicity of endotoxin and hemoglobin. J. Lab. Clin. Med. 108: 132-137.

38. Griffiths, E., A. Cortes, N. Gilbert, P. Stevenson, S. MacDonald, and D. Pepper. 1995. Haemoglobin-based blood substitutes and sepsis. Lancet. 345: $158-160$.

39. Langermans, J.A.M., and W.K. Bleeker. 1995. Haemoglobin-based blood substitutes and infection. Lancet. 345:863-864.

40. Walder, C.E., C. Thiemermann, and J.R. Vane. 1991. The involvemen of endothelium-derived relaxing factor in the regulation of renal cortical blood flow in the rat. Br. J. Pharmacol. 102:967-973.

41. Southan, G.J., S.S. Gross, and J.R. Vane. 1993. Amides and esters of $\mathrm{N}^{\mathrm{G}}$-nitro-L-Arginine (e.g., L-NAME) must be hydrolyzed to become active NO Synthase inhibitors. Br. J. Pharmacol. 109:9P.

42. Lorente, J.A., L. Landin, E. Renes, R. De Pablo, P. Jorge, E. Rodena, and D. Liste. 1993. Role of nitric oxide in the hemodynamic changes of sepsis. Crit. Care Med. 21:759-767.

43. Petros, A., G. Lamb, A. Leone, S. Moncada, D. Bennett, and P. Vallance. 1994. Effects of a nitric oxide synthase inhibitor in humans with septic shock. Cardiovasc. Res. 28:34-39.

44. Mundel, P., S. Bachmann, M. Bader, A. Fischer, W. Kunmmer, B. Mayer, and W. Kritz. 1992. Expression of nitric oxide synthase in kidney macula densa cells. Kidney Int. 42:1017-1019.

45. Wilcox, C.S., W.J. Welch, F. Murad, S.S. Gross, G. Taylor, R. Levi, and H.H. Schmidt. 1992. Nitric oxide synthase in macula densa regulates glomerular capillary pressure. Proc. Natl. Acad. Sci. USA. 89:11993-11997.

46. Shultz, P.J., and L. Raij. 1992. Endogenously synthesized nitric oxide prevents endotoxin-induced glomerular thrombosis. J. Clin. Invest. 90:17181725 